\title{
A Cartoon Sampler
}

\section{J A Y N. D A R L I N G}

Cartoonist and conservationist Jay Norwood Darling was born in 1876 in Norwood, Michigan. In 1886 his family moved to Sioux City, Iowa, where his father was minister of the First Congregational Church. As a youngster, Darling showed an interest in sketching and also in hunting and camping. By the time he was a student at Beloit College in Wisconsin, he began to sign his sketches "Ding," a contraction of Darling. In 1900 he graduated from college and joined the Sioux City Journal as a reporter and later a cartoonist. ${ }^{1}$

The year 1906 was an important one, as Darling married Genevieve (Penny) Pendleton and moved to Des Moines to work as a cartoonist for the Des Moines Register and Leader. His fame spread quickly and in 1911 he relocated eastward to join the New York Globe. While New York was intellectually stimulating, the Darlings missed the Midwest and in 1913 Ding rejoined the Des Moines Register and Leader. His reputation continued to grow and in 1916 his cartoons were syndicated nationally by the New York Herald Tribune in 130 newspapers. Twice, Darling received the Pulitzer Prize for editorial cartoons. Before his retirement in 1949, he drew about 15,000 cartoons and was regarded as one of the nation's leading cartoonists.

If cartooning was his life work, the conservation of natural resources was his real passion. He helped organize the Iowa Division of the Izaak Walton League of America and was active in creating the Men's Garden Clubs of America. Later he served on the Iowa State Fish and Game Commission and was responsible for the founding of Iowa State University's Cooperative Wildlife Research Unit. Even though he was a conser-

\footnotetext{
1 The details of Darling's life can be found in David L. Lendt, Ding, The Life of Jay Norwood Darling, Ames: Iowa State University Press, 1979.
} 
vative Republican and friend of Herbert Hoover, Darling was appointed Chief of the Bureau of Biological Survey, U.S. Department of Agriculture, in the administration of Franklin D. Roosevelt. While Chief of the Biological Survey in 1935 and 1936, he helped start the Federal Duck Stamp program and designed the first Duck Stamp. In addition he drew the symbol of the flying goose used by every Federal Wildlife Refuge. After leaving the survey and returning to the Register, Darling was president of the National Wildlife Federation. Conservation was also important in his cartoons, for he drew many decrying the exploitation of soil, water, and wildlife. For enjoyment, Darling made over 80 etchings, mostly of wildlife. ${ }^{2}$

From the time of his retirement in 1949 until his death in 1962, Darling contributed his papers to The University of Iowa Libraries. The collection includes correspondence, speeches, articles, leaflets, clippings, scrapbooks, and sketchbooks. In addition, about 6,500 full-size original editorial cartoon drawings covering the years from 1907 to 1948 are part of the holdings, one-third of Darling's output. There are engraver's proofs of the cartoons and also a number of original Darling drawings and prints. Nine Darling cartoons, representing a tongue-in-cheek history of education, were etched in metal and mounted above the main doors of The University of Iowa Main Library in 1953. They have since been moved inside to a fourth floor corridor. To make the cartoon collection useful for reference and research, a systematic index was created. This index enables the researcher to find a cartoon by date, title, subject, or even symbol (image). The Darling Collection is available for research use.

${ }^{2}$ Amy N. Worthen, The Prints of J. N. Darling, Ames: Brunnier Gallery and Museum, Iowa State University, 1984. 


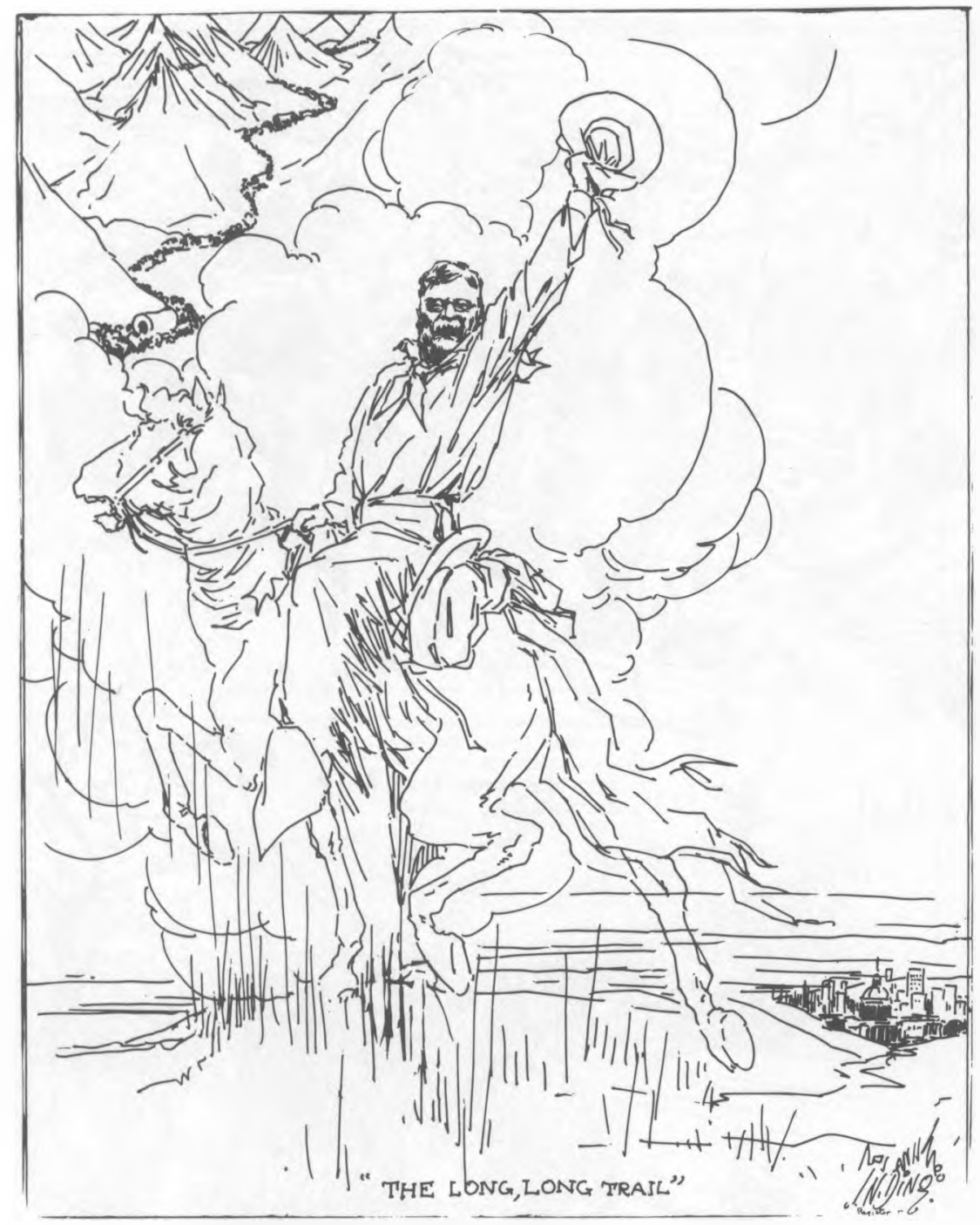

This cartoon was published at the time of the death of Theodore Roosevelt in 1919 and was probably Ding's most famous cartoon. 


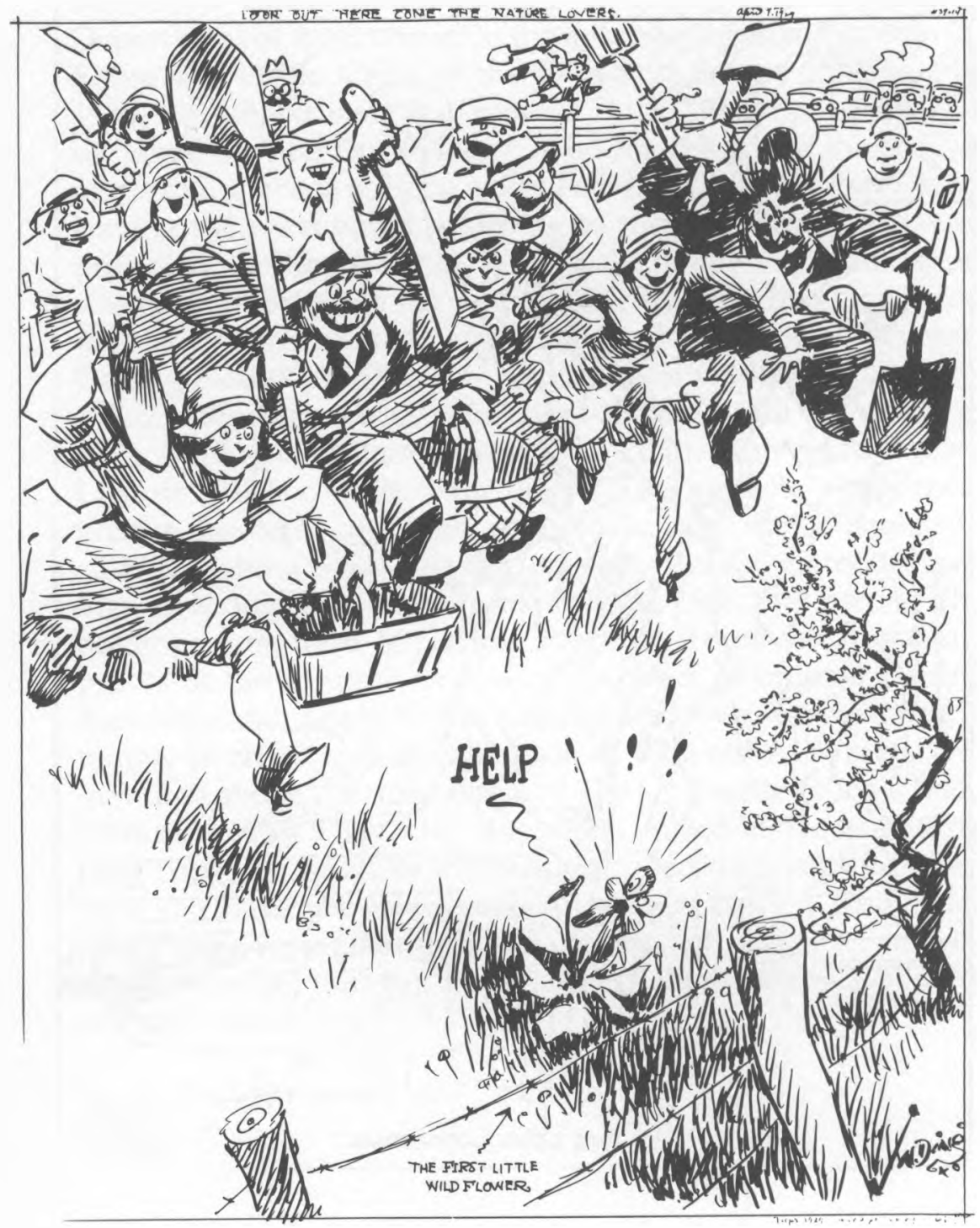




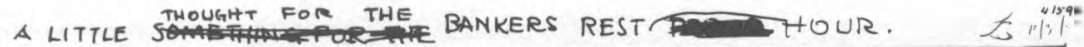
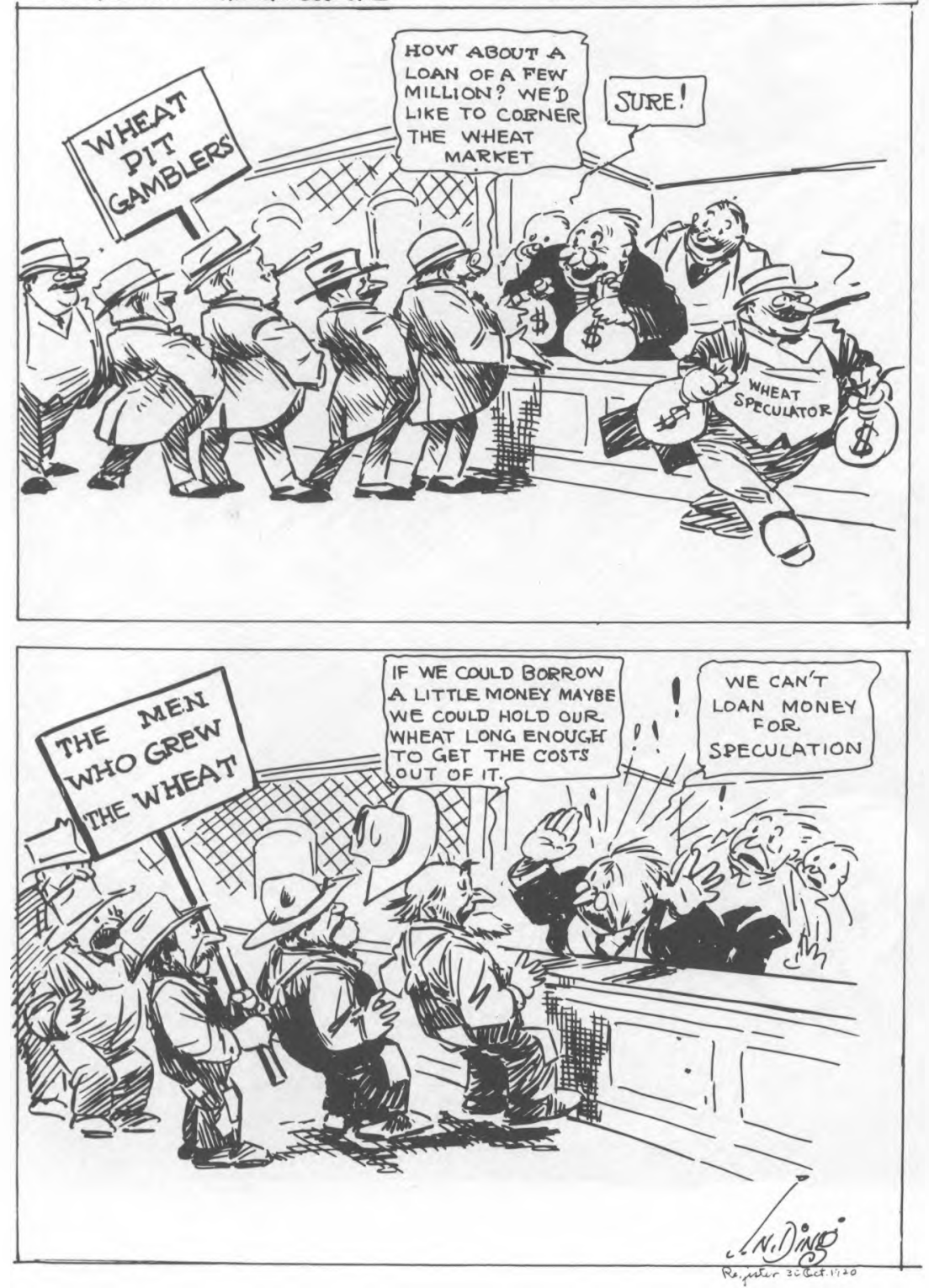


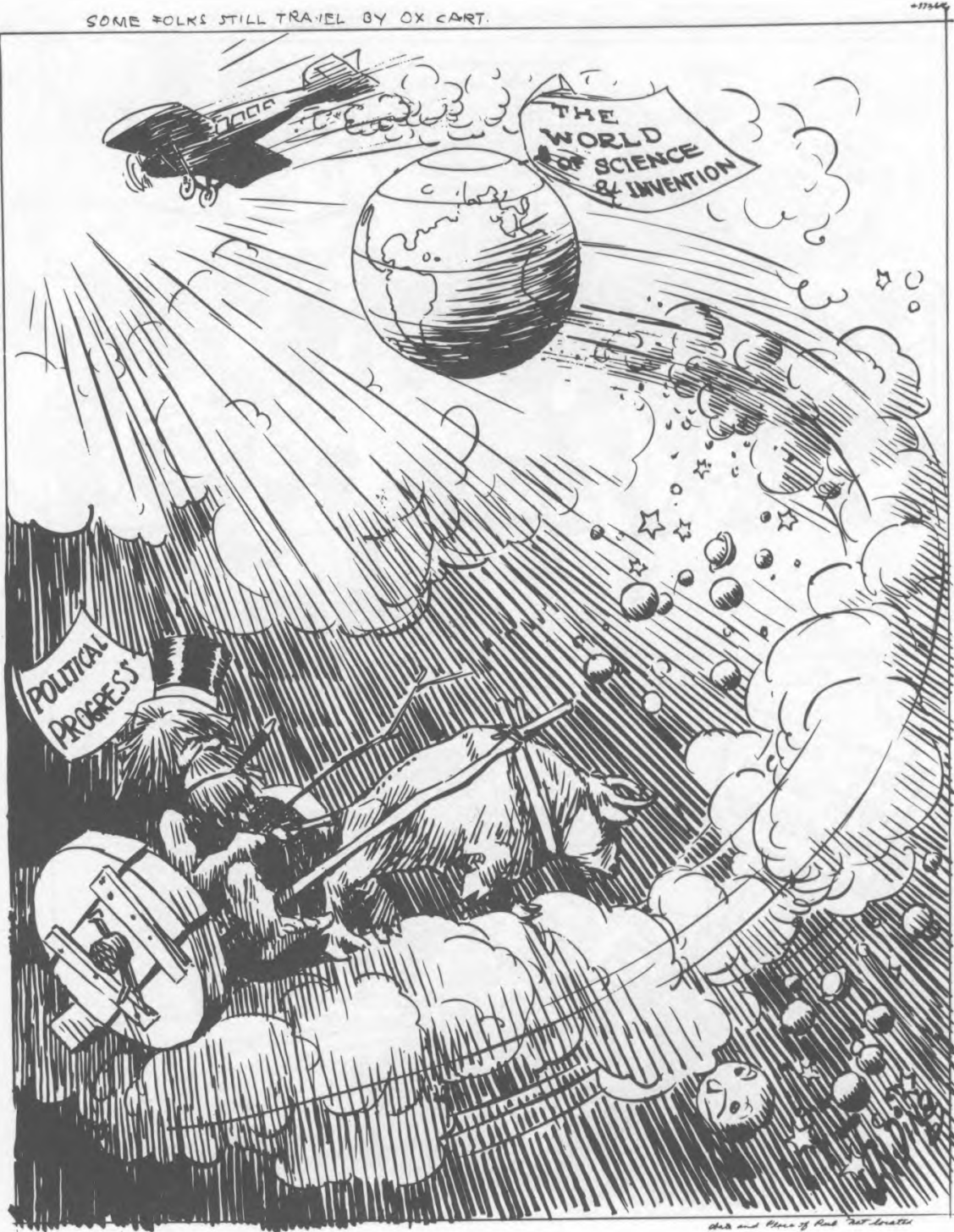




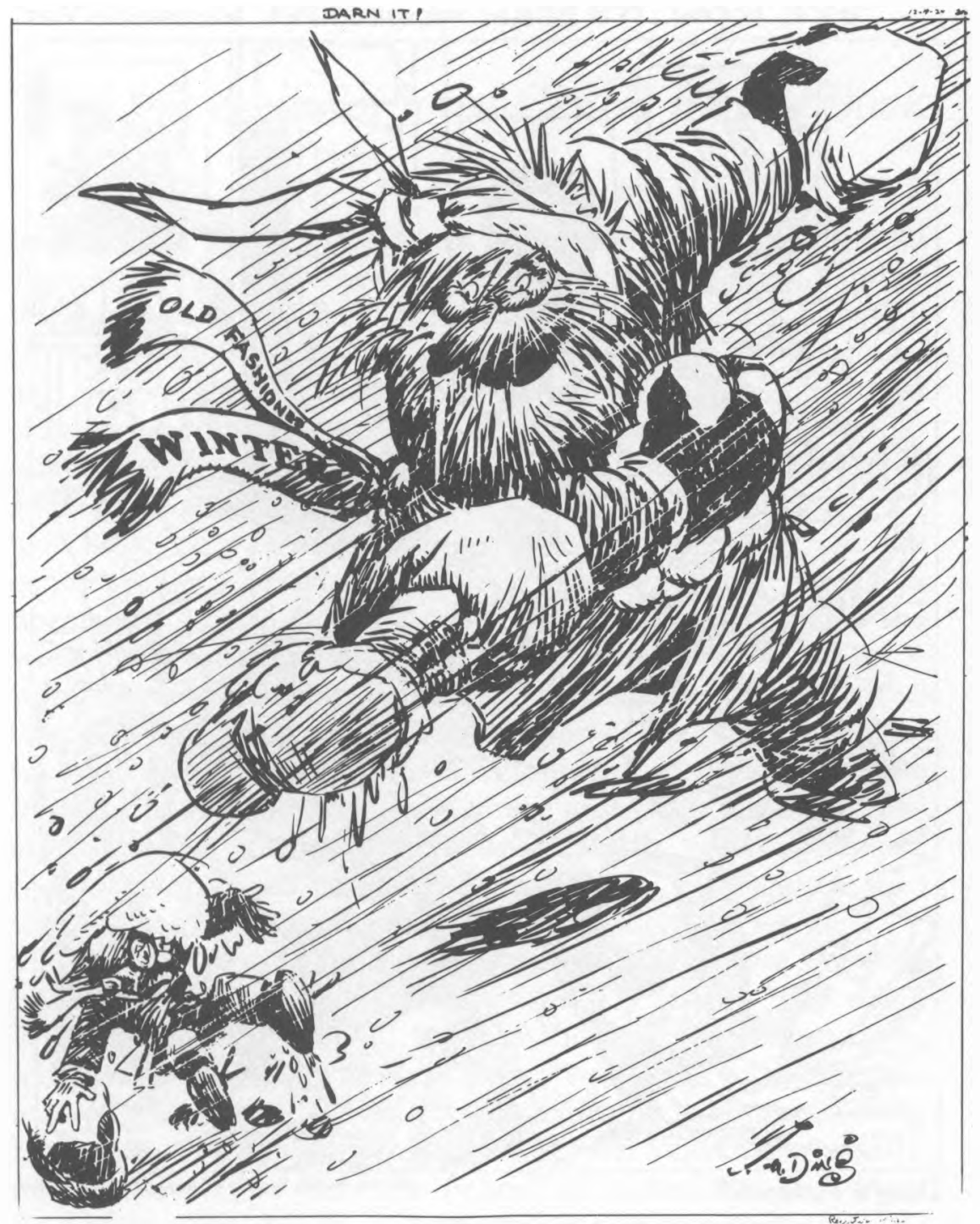


'BYE NOW_IT'S BEEN WONDERFUL KNOWING YOU.

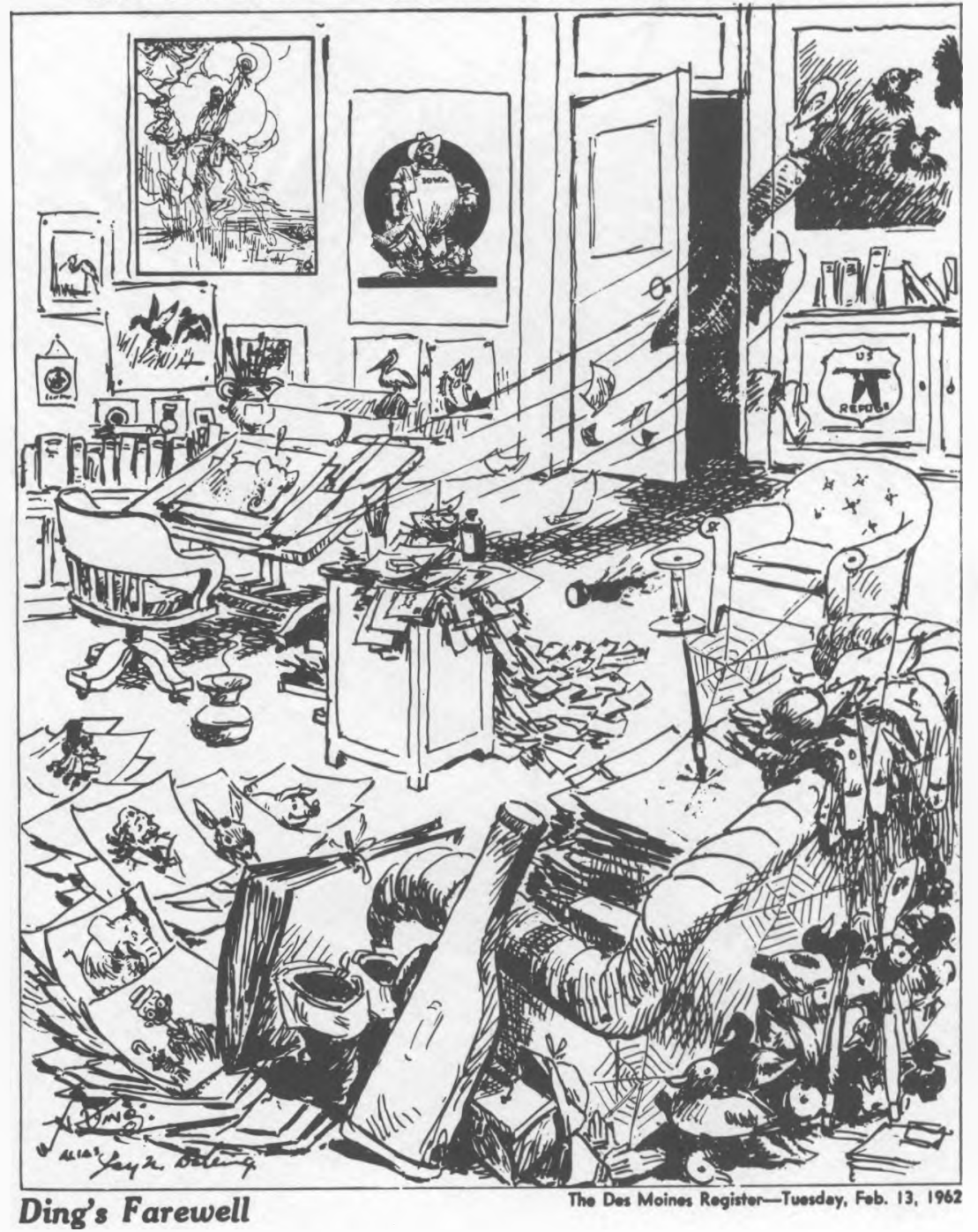

